\title{
PREPARATION AND EVALUATION OF SELF MICROEMULSIFYING DRUG DELIVERY SYSTEM FOR FEXOFENADINE HYDROCHLORIDE
}

\author{
*Akash M Patel, Jitul B Patel, Tejas B Patel, B. N. Suhagia,Tushar R Patel \\ Faculty of Pharmacy, Dharmsinh Desai University, Nadiad-387001, Gujarat, India \\ *Corresponding Author's E-mail:akash_patel26@yahoo.com
}

\begin{abstract}
Developing a drug product with desirable bioavailability is a challenge for sparingly water soluble drugs such as Fexofinadine hydrochloride. Objective: In the present investigation self microemulsifying drug delivery system (SMEDDS) of Fexofenadine hydrochloride was developed for improving solubility and dissolution rate of drug. Material Method: Solubility of Fexofenadine hydrochloride was determined in various non-aqueous vehicles such as oils, surfactants, and cosurfactants. Psuedoternary phase diagrams were constructed to identify the self-micro emulsification region. Four formulations of SMEDDS were selected from the optimum concentration of oils, surfactant, and co-surfactants from psuedoternary diagrams. Results and Discussion: Selected formulations were evaluated for droplet size, in-vitro drug dissolution, drug content and solubility of drug. The optimum formulation was $20 \%$ oleic acid, $26.3 \%$ ACONON MC 8 and 53.3\% PEG 400. Self-micro emulsification with the combination of oleic acid and ACONON MC 8 was found higher. Conclusion: The results obtained from in vitrodissolution indicated Fexofenadine hydrochloride in SMEDDS dissolved rapidly and completely in phosphate buffer $\mathrm{pH} 6.8$ which was used as dissolution medium.
\end{abstract}

Key-Words: SMEDDS, ACONON MC8, Dissolution enhancement, Psuedoternary phase diagrams

\section{INTRODUCTION}

SMEDDS is defined as isotropic mixture of lipid or oil, surfactant, co-surfactant and drug substance that rapidly form a fine oil-in-water microemulsionwhen exposed to aqueous media under condition of gentle agitation or digestive motility that would be encountered in the GIT.Self Emulsifying Drug Delivery Systems (SEDDS) andSMEDDS are the two types of self emulsifying systems ${ }^{1}$.Both SEDDS and SMEDDS have distinct features associated with improvement of drug delivery properties. SEDDS formulations are characterized by in vitro lipid droplet sizes of $200 \mathrm{~nm}$ to $5 \mathrm{~mm}$ and its dispersion has a turbid appearance ${ }^{2,3}$. SMEDDS, however, have a smaller lipid droplet size $(<100 \mathrm{~nm})$ and its dispersion has an optically clear to translucent appearance. Both systems are associated with the generation of large surface area upon dispersions resulting into increased absorption of poorly soluble drugs ${ }^{4,5,6}$.

Fexofenadine hydrochloride is an antihistaminic drug used in the treatment of hayfever and allergy symptoms. It is a third-generation antihistaminic agent. It does not readily pass through the blood-brain barrier, and hence causes less drowsiness than first-generation histamine-receptor antagonists. Fexofenadine hydrochloride has $33 \%$ absorption and 60-70 \% protein binding. Half life of drug is 14.4 hours. $\log \mathrm{P}$ and $\mathrm{pKa}$ values of drug are 5.6 and 13.2 respectively. Fexofenadine hydrochloride is poorly water soluble leading to lower absorption rate. Thus, there is a need to increase the solubility of drugto improve the absorption of drug via oral route.

Present investigation was aimed to increase oral bioavailability of Fexofenadine hydrochloride. Self microemulsifying drug delivery system was developed to enhance oral solubility and in-vitro dissolution of drug. SMEDDS are physically stable formulations that are easy to manufacture. Thus, for lipophilic drugs these systems may offer an improvement in the rate and extent of absorption and results in more reproducible plasma level concentrations.

\section{MATERIALS AND METHODS}

\section{Materials}

Fexofenadine hydrochloride was received as gift sample from Astron Research Centre, Ahmedabad, INDIA. ACONON MC8 was received as gift sample from ABITECH Corporation, INDIA. Aerosil200 was received as gift sample from Acron Pharmaceuticals, Ahmedabad, INDIA. Oleic acid, Polyethylene glycol 400 (PEG 400), Microcrystalline cellulose (MCC) was purchased from S. D. Fine Chemicals, Mumbai, INDIA. All other reagents used were of analytical grade.

\section{Experimental Methods}

\section{Solubility studies}

Excess amount of Fexofenadine hydrochloride was added to $2 \mathrm{ml}$ of each excipients were placed in test tubes and the mixture was vortexed and heated in a water bath to facilitate drug solubilization. The mixture was finally kept at ambient room temperature $\left(25^{\circ} \mathrm{C}\right)$ under continuous shaking for 24 hours to attain equilibrium. Aliquots of supernatant were diluted with phosphate buffer ( $\mathrm{pH}-6.8)$ and the drug content was measured at $220 \mathrm{~nm}$ using a UV spectrophotometer. ${ }^{7,8,9}$ Excipients used in solubility study were water, span 80 , castor oil, oleic acid, polyethylene glycol 400, transcutol P, acconon MC8, isopropyl alcohol (IPA), LabrafilM1944 $\mathrm{C}_{\mathrm{s}}$, tween 80, and cremophore RH40.

\section{Construction of Psuedoternary Phase Diagrams}

Self micro-emulsifying performance of Self Microemulsion (SME) mixture was assessed from their 
ternary phase diagrams. Only the specific combinations of oil, surfactant and a co surfactant in the specific composition range were observed to produce a fine microemulsion upon aqueous dilution ${ }^{10,}{ }^{11}$. To check emulsification efficiency of SME mixtures, test for emulsification was performed on all combinations and the resultant dispersions were visually assessed. The dispersions either formed a clear microemulsion, a slightly turbid emulsion or a milky emulsion which immediately was phase separated ${ }^{12,} 13,14$. Nine combinations were prepared with the ratios of oil:(surfactant/co-surfactant) as $1: 1,1: 2,1: 3,1: 4,1: 5,1: 6,1: 7,1: 8$ and $1: 9$. The surfactant/co-surfactant ratios $\left(\mathrm{K}_{\mathrm{m}}\right)$ of $1: 1,1: 2,2: 1$ and $3: 1$ were evaluated. Surfactant and co-surfactant mixtures possessing various $\mathrm{K}_{\mathrm{m}}$ ratios were prepared by weighing appropriate quantities of surfactant and co-surfactant and were vortexed for $30 \mathrm{~min}$ to produce a homogenous mixture.
Mixtures with $12-50 \%$ of the oil, $25-66 \%$ of the surfactant and $12-44 \%$ of co-surfactant were evaluated for their self emulsifying properties. These mixtures were then mixed with the oil phase to form an isotropic SME mixture. Thus, each combination had a total of 9 samples with different proportions of oil, surfactants and co-surfactants. ${ }^{15,16}$

\section{Preparation of SMEDDS}

Liquid SMEDDS formulation was prepared by dissolving $100 \mathrm{mg}$ of Fexofenadine Hydrochloride in the optimized SMEDDS mixture consisting of oleic acid, Aconon MC8 and PEG 400.Drug containing mixture was vortexed until a clear solution was obtained. These mixtures were observed for any signs of turbidity or phase separation for a period of 48 hours. Composition of Liquid SMEDDS for Fexofenadine Hydrochloride is shown in Table 1.

Table 1: Composition of Fexofenadine SMEDDS

\begin{tabular}{|c|c|c|c|c|c|}
\hline Batch & $\mathrm{K}_{\mathrm{m}}$ ratio & $\begin{array}{l}\text { Drug } \\
\text { (mg) }\end{array}$ & $\begin{array}{l}\text { Oil } \\
(\%)\end{array}$ & $\begin{array}{l}\text { Surfactant } \\
(\%)\end{array}$ & Co-Surfactant (\%) \\
\hline $\mathrm{F} 1$ & $1: 1$ & 100 & 25 & 37.5 & 37.5 \\
\hline $\mathrm{F} 2$ & $1: 2$ & 100 & 20 & 26.3 & 53.3 \\
\hline F3 & $2: 1$ & 100 & 16.6 & 55.5 & 27.7 \\
\hline $\mathrm{F} 4$ & $3: 1$ & 100 & 50 & 37.5 & 12.5 \\
\hline \multicolumn{6}{|c|}{$\begin{array}{l}\text { Drug: Fexofenadine hydrochloride } \\
\text { Oil: Oleic acid } \\
\text { Surfactant: Acconon MC } 8 \\
\text { co-surfactant: Polyethylene Glycol } 400 \\
K_{m} \text { ratio: Surfactant : co-surfactant ratio }\end{array}$} \\
\hline
\end{tabular}

\section{Preparation of Solid SMEDDS (S-SMEDDS)}

The optimized liquid SMEDDS formulation was converted into free flowing powder by adsorption of liquid SMEDDS onto solid carriers. The solid carriers used for adsorption comprised of materials that provided a high surface area with good disintegration characteristics ${ }^{17,}{ }^{18}$. The solid carriers used include microcrystalline cellulose (MCC) and colloidal silicon dioxide (Aerosil 200). High levels of adsorption up to $95 \%(\mathrm{w} / \mathrm{w})$ can be observed with the carriers chosen. The conversion process involved addition of liquid formulation on to carriers under continuous mixing in a blender. The optimized ratio for MCCand Aerosil 200 was 1:1 which was used for preparingSSMEDDS of all batches. The S-SMEDDS powder was used for further evaluation of parameters. The powder was dried and filled directly into capsules.

\section{Characterization of SMEDDS}

\section{Test for Self Emulsification}

$0.5 \mathrm{~mL}$ of sample mixture placed in $400 \mathrm{~mL}$ of water and contents were agitated with magnetic stirrer. The spontaneity of emulsification, clarity of dispersion, and apparent stability evaluated. The optimized formulation emulsified into a clear, transparent microemulsion and showed no signs of instability for 24 hours.

\section{Particle size of SMEDDS}

The Particle size of the resultant liquid SMEDDS was measured using Dynamic Light Scattering (Malvern Zeta analyzer Particle Sizing Systems). The liquid SMEDDS samples were taken in disposable glass tubes (VWR Scientific products) and particle size was determined.

\section{Drug Content}

$10 \mathrm{~mL}$ petroleum ether was added to $1 \mathrm{~mL}$ of liquid SMEDDS containing Fexofenadine hydrochloride and mixed by shaking. The mixture was vortexed and centrifuged at $1000 \mathrm{rpm}$ for 3 minutes.Finally, the upper liquid phase was collected and assayed spectrophotometrically for the drug content at the wavelength $220 \mathrm{~nm}$ with proper dilution of petroleum ether as blank.

\section{In-vitro drug release studies of SMEDDS}

In-vitro drug release studies from liquid SMEDDS were performed using USP Type I dissolution apparatus (basket apparatus) at $100 \mathrm{rpm}$. Liquid SMEDDS preparation equivalent to $100 \mathrm{mg}$ Fexofenadine Hydrochloride was filled into soft gelatin capsule. The dissolution medium consisted of $900 \mathrm{ml}$ of phosphate buffer $\mathrm{pH} 6.8$ maintained at $37 \pm 0.5^{\circ} \mathrm{C}$. At predetermined time intervals $5 \mathrm{ml}$ of aliquot was withdrawn, and an equivalent volume of fresh dissolution medium was immediately added. The amount of drug released was estimated by measuring absorbance at $220 \mathrm{~nm}$ using a spectrophotometer.

\section{Angle of repose}

A funnel was kept vertically in stand at a specified height above a paper placed on horizontal surface. The bottom 
was closed and $10 \mathrm{gm}$ of sample powder was filled in funnel. The funnel was opened to release the powder on paper to form a smooth conical heap. The height of heap was measured using the scale. A border of heap was marked circularly and its diameter was measured at four points. The average diameter was calculated and radius was found out from it. The angle of repose was calculated using following formula:

$$
\tan \theta=h / r
$$

Where; $\mathrm{h}=$ height of the heap, $\mathrm{r}=$ radius of the heap

\section{In-vitro Drug Release Studies From S-SMEDDS}

In vitro drug release studies from S-SMEDDS were performed using USP Type I dissolution apparatus (dissolution tester) with number of basket rotations set to $50 \mathrm{rpm}$. The dissolution medium consisted of $900 \mathrm{~mL}$ of phosphate buffer pH 6.8 maintained at $37 \pm 0.5^{\circ} \mathrm{C}$. SSMEDDS containing $100 \mathrm{mg}$ of Fexofenadine Hydrochloride was introduced into a gelatin capsule shell and was put into the dissolution medium. At predetermined time intervals $5 \mathrm{~mL}$ of aliquot was withdrawn and an equivalent volume of fresh dissolution medium was immediately added. The amount of drug released was estimated by measuring absorbance at $220 \mathrm{~nm}$ using a Double beam spectrophotometer (Shimanzdu UV 1800 spectrophotometer). Dissolution of liquid SMEDDS and marketed preparation was also determined in identical manner. The calibration curve of drug was made in phosphate buffer $\mathrm{pH} 6.8$ and at $220 \mathrm{~nm}$.

\section{RESULTS AND DISCUSSION}

Solubility studies
Solubility study of drug in different oils, surfactant, cosurfactant was shown in Table 2. According to that Fexofenadine hydrochloride showed higher solubility in oleic acid, acconon MC8 and PEG 400. Solubility of drug in oleic acid was found $6.38 \pm 005 \mathrm{mg} / \mathrm{mL}$. Solubility of drug in Acconon MC8 was found $22.48 \pm 0.38 \mathrm{mg} / \mathrm{mL}$.

Table 2: Solubility of Fexofenadine Hydrochloride in various Solvents

\begin{tabular}{|l|l|}
\hline Solvents & Solubility $(\mathbf{m g} / \mathbf{m L}) \pm$ SD \\
\hline Water & $1.62 \pm 0.05$ \\
\hline Span 80 & $11.56 \pm 0.04$ \\
\hline Castor Oil & $0.38 \pm 0.02$ \\
\hline Oleic Acid & $6.38 \pm 0.05$ \\
\hline PEG 400 & $17.12 \pm 0.4$ \\
\hline Transcutol P & $15.13 \pm 0.5$ \\
\hline Acconon MC8 & $22.46 \pm 0.38$ \\
\hline IPA & $20.57 \pm 0.26$ \\
\hline Labrafil M1944 $\mathrm{C}_{\mathrm{s}}$ & $0.24 \pm 0.05$ \\
\hline Tween 80 & $13.27 \pm 0.14$ \\
\hline Cremophore RH40 & $9.67 \pm 0.27$ \\
\hline
\end{tabular}

Ternary Phase diagrams

Solubility of drug in mixture of oleic acid, Acconon MC8 and PEG 400 were selected for construction of pseudoternary phase diagrams. Total nine combinations were prepared. Phase diagrams for various ratios of surfactant and co-surfactant $(1: 1,1: 2,2: 1,3: 1)$ were constructed. $^{19}$ The phase diagrams for surfactant- cosurfactant ratio 1:1, 1:2, 2:1, 3:1 were shown in Figure 1, 2, 3 and 4 respectively. Phase diagrams for $K_{m}$ ratio $1: 1$ and 1:2 was quite similar while phase diagrams for $K_{m}$ Ratio 2:1 and 3:1 were similar.

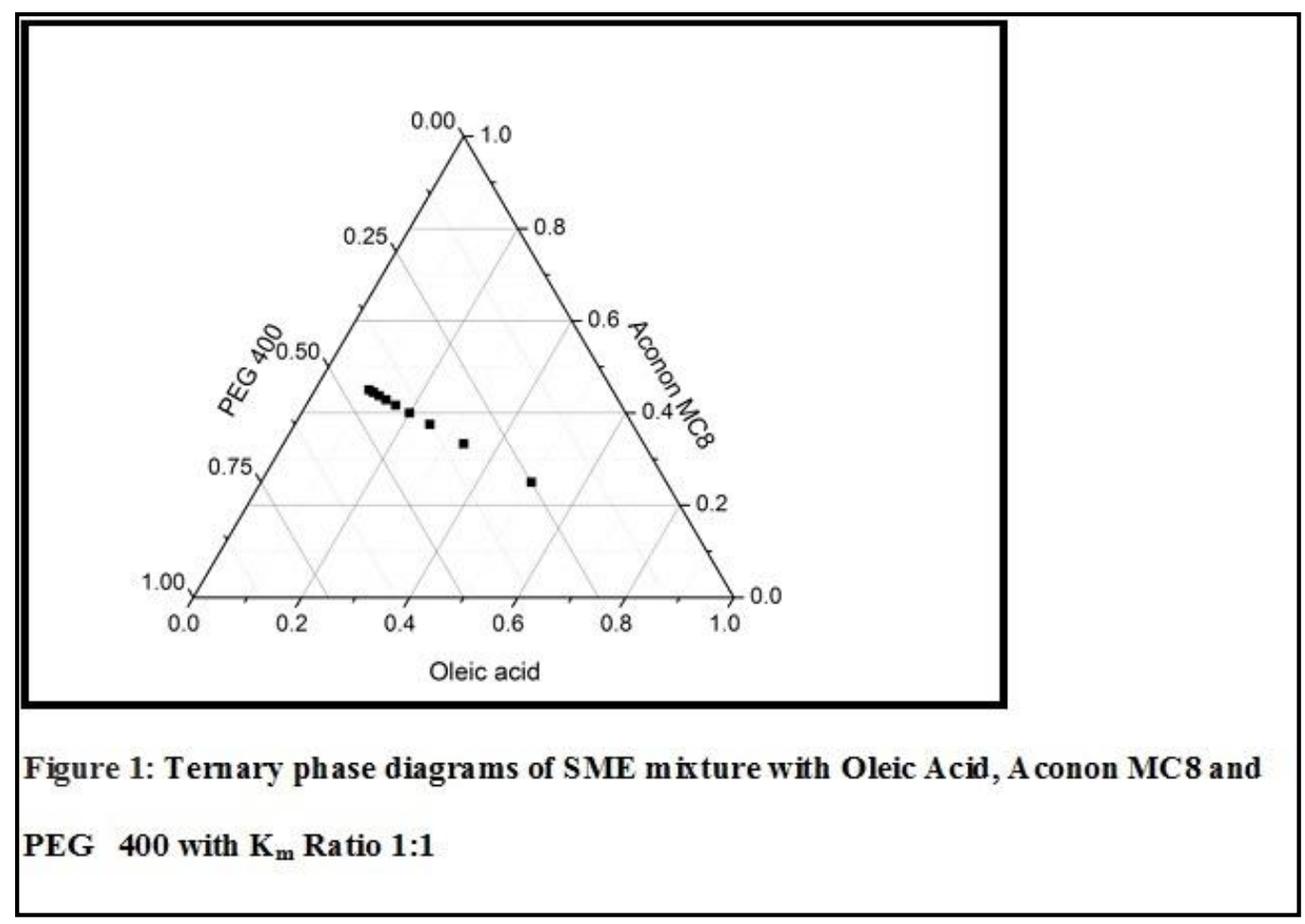




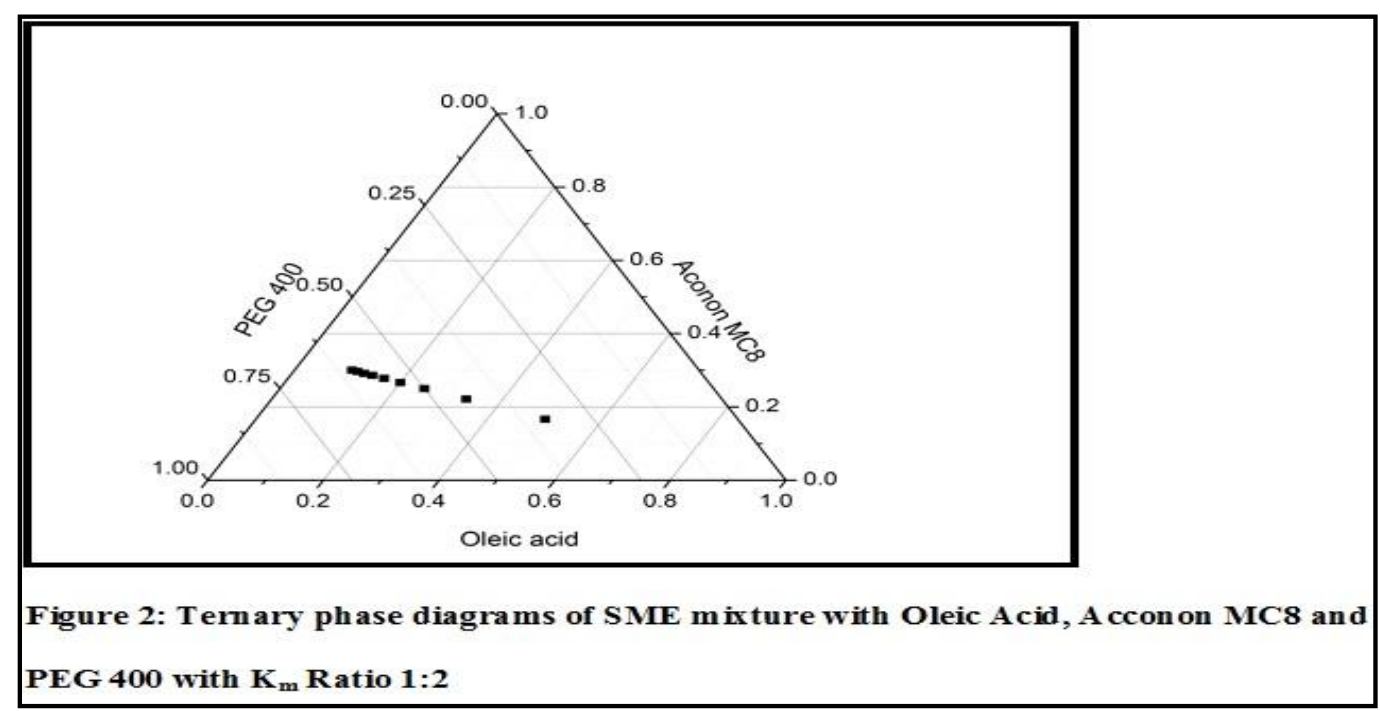

From the results of self emulsification time, droplet size and visual inspection of all the combination of $\mathrm{K}_{\mathrm{m}}$ ratio $1: 1$, 1:2, 2:1 and 3:1, four batches were selected as best formulation for preparation of liquid SMEDDS. Ratio of oleic Acid, Acconon MC8 and PEG 400 for $\mathrm{K}_{\mathrm{m}}$ ratio 1:1, 1:2, 2:1 and 3:1 were presented in Table 3. All four combinations were also evaluated for particle size, self emulsification time and visual Inspection.

Self microemulsifying performance of SME mixture was assessed from their ternary phase diagrams and time taken to produce a fine microemulsion. To check emulsification efficiency of SME mixtures, test for emulsification was performed on all combinations and the resultant dispersions were visually assessed. Resulting dispersions either formed a clear microemulsion, a slightly turbid emulsion or a milky emulsion which immediately phase separate. ${ }^{20,21,22,23}$

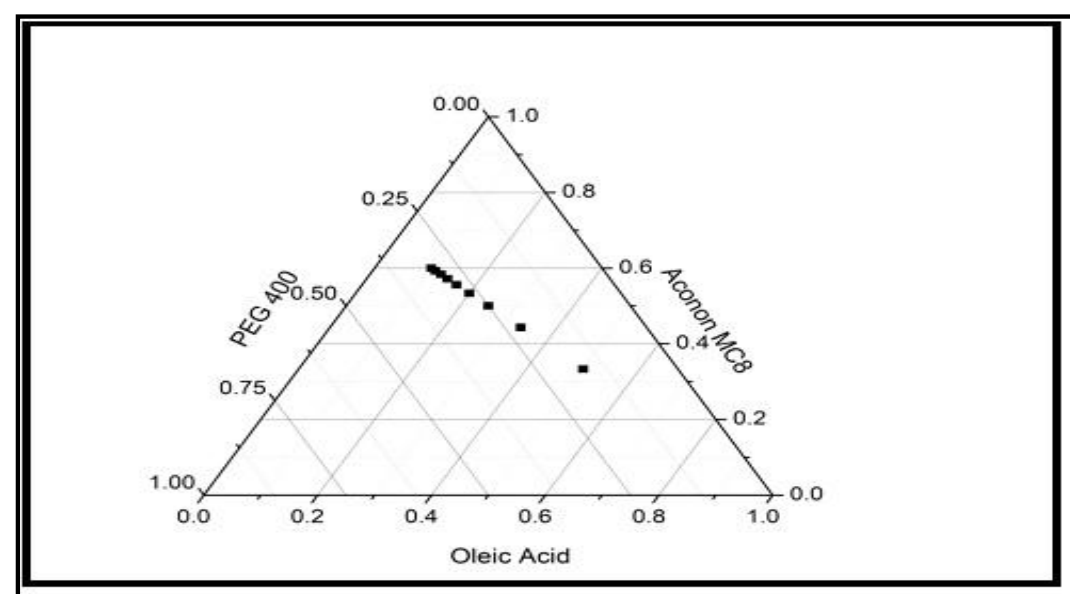

Figure 3: Ternary phase diagrams of SME mix ture with Oleic Acid, A conon MC8 and PEG 400 with $K_{m}$ Ratio 2:1

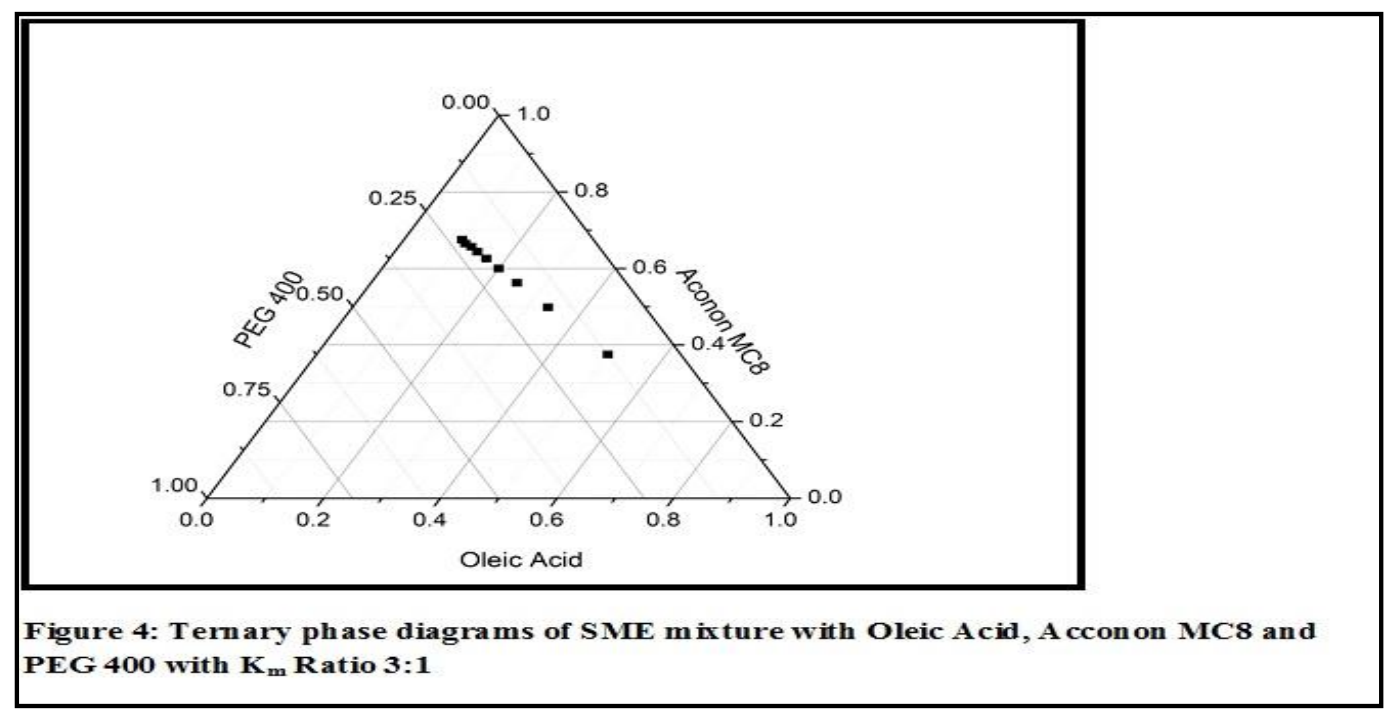


Table 3: Composition of Liquid SMEDDS

\begin{tabular}{|c|c|c|c|c|c|}
\hline Batch & $\mathbf{K}_{\mathbf{m}}$ ratio & Drug(mg) & Oil (\%) & Surfactant(\%) & Co-Surfactant (\%) \\
\hline F1 & $1: 1$ & 100 & 25 & 37.5 & 37.5 \\
\hline F2 & $1: 2$ & 100 & 20 & 26.3 & 53.3 \\
\hline F3 & $2: 1$ & 100 & 16.6 & 55.5 & 27.7 \\
\hline F4 & $3: 1$ & 100 & 50 & 37.5 & 12.5 \\
\hline
\end{tabular}

\section{Characterization of Liquid SMEDDS}

\section{Test for Self Emulsification}

The SMEDDS formed either a visually clear microemulsion, or a slightly turbid emulsion, or a milky emulsion that immediately phase separated. The optimized formulation emulsified into a clear, transparent microemulsion and showed no signs of instability for 24 hours. Results of self-emulsification time were shown in Table 4.

Table 4: Self Emulsification Time of Batches F1-F4

\begin{tabular}{|c|c|c|c|}
\hline Batch & $\mathbf{K}_{\mathbf{m}}$ ratio & Self Emulsification Time (Second) & Visual Observation \\
\hline F1 & $1: 1$ & 45 & Good \\
\hline F2 & $1: 2$ & 42 & Good \\
\hline F3 & $2: 1$ & 62 & Good \\
\hline F4 & $3: 1$ & 56 & Good \\
\hline
\end{tabular}

\section{Particle size analysis}

The Particle size of the liquid SMEDDS is important since it determines the rate and extent of drug release and absorption. The drug can diffuse faster from smaller droplets into the aqueous phase, thereby increasing the drug dissolution. Smaller droplet size presents large surface area for drug absorption. ${ }^{24}$ Increase in surfactant concentration decreases the droplet size up to a certain level but thereafter anyfurther increase results in an increase in droplet size. The reduction in droplet size can be attributed to the stabilization of oil droplets due to localization of surfactant monolayers at the oil-water interface. ${ }^{25}$ Increase in surfactant concentration causes enhanced water penetration into oil droplets leading to breakdown of oil droplets and resultant bigger droplets. The droplet size of the nanoemulsion was measured using dynamic light scattering. The loaded SMEDDS displayed a Gaussian distribution of droplet sizes. ${ }^{26,27,}{ }^{28}$ Theparticle size of the resultant Liquid SMEDDS was measured using Dynamic Light Scattering (Malvern Zeta Analyser Particle Sizing Analyser). Results of particle size analysis as presented in Table 5. Particle size of batch F1 and F4 were found to be $117.3 \mathrm{~nm}$ and $166 \mathrm{~nm}$ respectively. Batch F2 and F3 showed lower particle size $57.30 \mathrm{~nm}$ and $61.21 \mathrm{~nm}$.

Table 5: Average particle size of liquid SMEDDS

\begin{tabular}{|l|l|l|l|l|}
\hline Batch & $\mathbf{K}_{\mathbf{m}}$ ratio & Size(nm) & \% Intensity & Width(nm) \\
\hline F1 & $1: 1$ & 117.3 & 100 & 20.56 \\
\hline F2 & $1: 2$ & 57.30 & 97.4 & 7.14 \\
\hline F3 & $2: 1$ & 61.21 & 88.5 & 10.47 \\
\hline F4 & $3: 1$ & 166 & 100 & 26.14 \\
\hline \multicolumn{2}{|r|}{$K_{m}$ ratio: Surfactant- co-surfactant ratio } \\
\hline
\end{tabular}

\section{Drug Content}

All the batches F1-F4 were assayed spectrophotometrically for the drug content at the wavelength $220 \mathrm{~nm}$ with proper dilution of formulations taking phosphate buffer (PH-6.8) as blank ${ }^{29,30}$. Results of content uniformity were shown in Table 6. It showed all the batches have a minimum of $98 \%$ content uniformity. Among all the batches F2 had highest content uniformity $99.12 \%$.

Table 6: \% Drug Content

\begin{tabular}{|c|c|}
\hline Batch & \% Drug Content \pm SD \\
\hline F1 & $98.45 \pm 0.04$ \\
\hline F2 & $99.12 \pm 0.24$ \\
\hline F3 & $97.38 \pm 0.08$ \\
\hline F4 & $98.52 \pm 0.17$ \\
\hline
\end{tabular}

\section{Drug release studies of SMEDDS}

The in vitro dissolution of the Liquid SMEDDS Formulation F1-F4 was performed in phosphate buffer of pH 6.8 using a USP Type I dissolution apparatus with a basket speed of 100 RPM. Liquid SMEDDS dissolution medium and were sampled at regular intervals until complete drug release was observed. The amount of drug released was calculated from the calibration curve of Fexofenadine Hydrochloride. In vitro dissolution curve of batches F1 to F4 were shown in Figure 5. According to results batch $\mathrm{F} 3$ and $\mathrm{F} 4$ were found to have complete drug release in $140 \mathrm{~min}$ and $180 \mathrm{~min}$ respectively. Both F1 and F2 showed complete drug release in 70 and 80 min. Higher dissolution rate of batch F1 and F2 was observed due to lower globule size of liquid SMEDDS. From the of invitro drug release data, content uniformity and particle size 
batch F2 was selected as optimized batch for preformulation of solid SMEDDS.

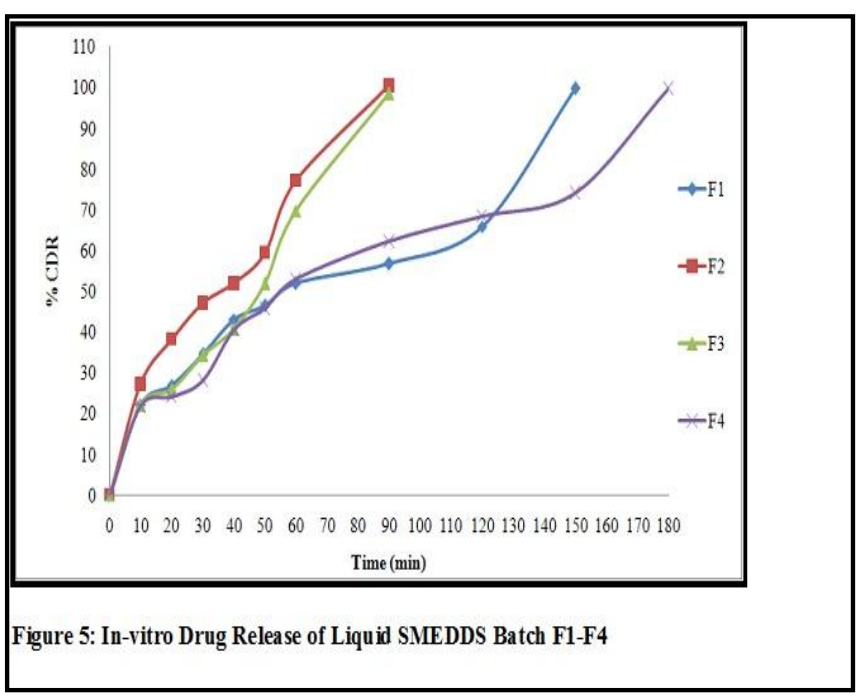

\section{Angle of Repose}

Angle of Repose of all four Batch F1-F4 was found with having good flow properties. Batch F1, F2, F3 and F4 having angle of repose $24.17 \pm 0.017,26.32 \pm 0.24,28.56$ $\pm 0.053,24.83 \pm 0.64$ respectively.

\section{In vitro drug release studies From Solid SMEDDS}

The in-vitro dissolution of the Solid SMEDDS Formulation F1 to F4 was performed in phosphate buffer of $\mathrm{pH} 6.8$ using a USP Type I dissolution apparatus with a basket speed of 100 RPM. Solid SMEDDS dissolution medium and were sampled at regular time intervals until complete drug release was observed. The amount of drug released was calculated from the calibration curve of Fexofenadine Hydrochloride. Figure 6 showed in-vitro dissolution curve of solid SMEDDS. According to that almost complete drug release was observed within $90 \mathrm{~min}$ which was compared with marketed product and liquid SMEDDS.

\section{REFERENCES}

1. Yellela SR, Krishnaiah, Pharmaceutical Technologies for Enhancing Oral Bioavailability of Poorly Soluble Drugs; J Bioequi Bioav,2008,2(2),1-9

2. Suman K, Chandrasekhar VSR, Balaji. P, Approaches for the development of solid self-emulsifying drug delivery systems and dosage forms, Asian J of PharmSci 2009, 4(4),240-253.

3. Rajesh BV, Reddy TK, Srikanth G, Mallikarjun V, Nivethithai P, Lipid based self-emulsifying drug delivery system (sedds) for poorly water-soluble drugs: a Review, JGlob Pharm Tech.2010,2(3),47-55.

4. Kumar A, Sharma S, Ravindra K, Self Emulsifying Drug Delivery System: Future Aspects; Int J Pharm PharmSci, 2010, 2(4),7-13.

5. Porter CJH, Trevaskis NL, Charman WN, Lipids and lipid-based formulations: optimizing the oral delivery of lipophilic drugs. Nat Rev Drug Disco, 2007,6(3),231-248.

6. Chang RK, Shojaei AH, Effect of a lipoidic excipient on the absorption profile of compound UK 81252 in dogs after oral administration. J Pharm PharmSci, 2004,7(1),8-12.

7. Porter CJH, Enhancing intestinal drug solubilisation using lipidbased delivery systems. Adv Drug Deli Rev, 2008,60(6),673-691.

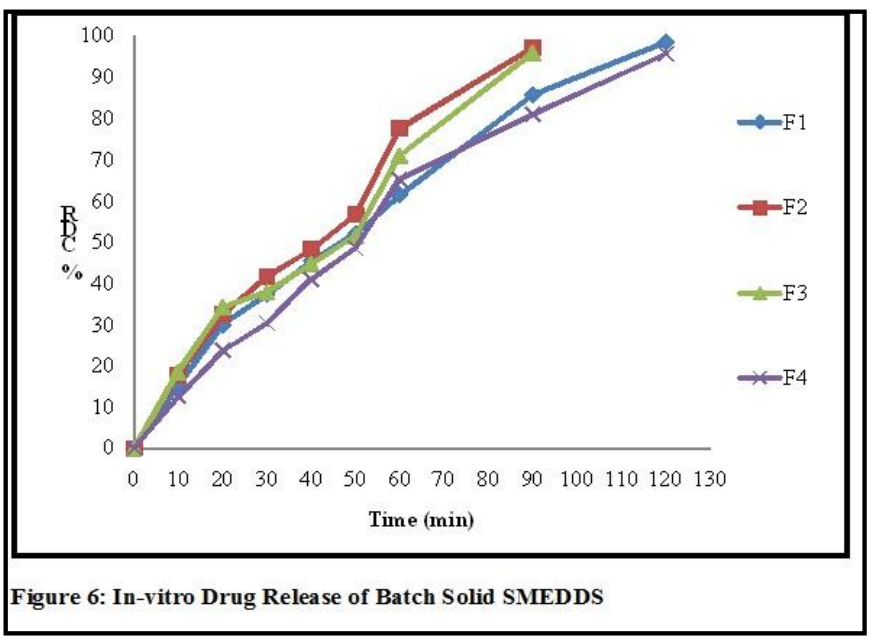

\section{CONCLUSION}

A particular SME mixture comprising of oleic acid, Aconon MC8 and PEG 400 was selected and optimized for the purpose for delivering Fexofenadine hydrochloride. Four different formulations of different $\mathrm{K}_{\mathrm{m}}$ ratio were prepared. Among this four prepared formulations of Liquid SMEDDS, formulation F2 containing 20\% oil, $26.3 \%$ surfactant and $53.3 \%$ co-surfactant was selected as optimized formulation. Optimized formulation had $57.30 \mu \mathrm{m}$ particle size and complete drug release in 90 minutes.In conclusion, Self emulsifying drug delivery systems were a promising approach for the formulation of Fexofenadine Hydrochloride. The oral delivery of hydrophobic drugs can be made possible by SMEDDSs, which have been shown to substantially improve oral bioavailability.

\section{ACKNOWLEDGEMENT}

The authors wishes to acknowledge AstronResearch Centre, Ahmedabad, INDIA for giving Fexofenadine hydrochloride as gift sample and AbitechCorporation, INDIA for providing ACONON MC8 as gift sample.

CONFLICT OF INTEREST: The author(s) do not have any conflict of interest.
8. Shah N, Self-emulsifying drug delivery systems (SEDDS) with polyglycolyzed glycerides for improving in vitro dissolution and oral absorption of lipophilic drugs. Intj pharm, 1994,106(1),15-23

9. Hauss DJ, Lipid based delivery systems for improving the bioavailability and lymphatic transport of a poorly water soluble LTB4 inhibitor. J Pharm Sci, 1998,87(2),164-169

10. Neslihan Gursoy R, Benita S, Self-emulsifying drug delivery systems (SEDDS) for improved oral delivery of lipophilic drugs. Biomed Pharmaco, 2004,58(3),173-182

11. Murdandea SB, Gumkowskia MJ, Development of a selfemulsifying formulation that reduces the food effect for torcetrapib. Int J of Pharm, 2008,351,15-22

12. Lawrence MJ, Rees GD, Microemulsion-based media as novel drug delivery system, Adv Drug Deli Rev, 2000,45,89-121.

13. Hauss DJ, Fogal SE, Ficorilli JV, Price CA, Roy T, Jayaraj AA, Keirns JJ, Lipid-based delivery systems for improving the bioavailability and lymphatic transport of a poorly water-soluble LTB4 inhibitor. J of Pharm Sci 1998,87, 164- 169.

14. Karim A, Gokhale R, Cole M, Sherman J, Yeramian P, Bryant M, Franke H, HIV protease inhibitor SC-52151: a novel method of optimizing bioavailability profile via a microemulsion drug delivery system. Pharm Res, 1994, 11, 368. 
15. Swenson ES, Milisen WB, Curatolo W., Intestinal permeability enhancement: efficacy, acute local toxicity and reversibility. Pharm Res 1994,11, 1132-42.

16. Tang B, Development of solid self-emulsifying drug delivery systems: preparation techniques and dosage forms. Drug Disco Today, 2008, 13(13-14), 606-612.

17. Carli F, Chiellini E, Pharmaceutical composition comprising a water/oil/water double microemulsion incorporated in a solid support. 2004, Google Patents.

18. T Yi., A new solid self-microemulsifying formulation prepared by spray-drying to improve the oral bioavailability of poorly water soluble drugs. Eur JPharmBiopharm, 2008,70(2),439-444

19. Cole ET, Cadé D, Benameur H, Challenges and opportunities in the encapsulation of liquid and semi-solid formulations into capsules for oral administration. Adv Drug Del Rev, 2008,60(6), 747-756

20. Chambin O, Influence of cryogenic grinding on properties of a self-emulsifying formulation. Int jpharm, 2004,278(1),79-89

21. Myers SL, Shively $\mathrm{ml}$, Preparation and characterization of emulsifiable glasses: Oil-in-water and water-in-oil-in-water emulsions. J coll and inter sci, 1992,149(1),271-278

22. Porter CJH, Evaluation of emulsifiable glasses for the oral administration of cyclosporin in beagle dogs. Int $\mathrm{j}$ pharm, 1996,141(1-2),227-237

23. Vyas S, Preparation and characterization of griseofulvin dry emulsion. Die Pharmazie, 1992, 47(6),463-464
24. Jang DJ, Improvement of bioavailability and photostability of amlodipine using redispersible dry emulsion. Eur J Pharm Sci, 2006,28(5),405-411

25. Nazzal S, Preparation and in vitro characterization of a eutectic based semisolid self-nanoemulsified drug delivery system (SNEDDS) of ubiquinone: mechanism and progress of emulsion formation. Intj pharm, 2002, 235(1-2),247-265

26. Serajuddin ATM, Preformulation study of a poorly water-soluble drug, -pentyl-3-(2-quinolinylmethoxy) benzenemethanol: Selection of the base for dosage form design. J Pharm Sci, 1986, 75(5),492-496

27. Attama AA, Kemnele MON, In vitro evaluation of drug release from self micro-emulsifying drug delivery systems using a biodegradable homolipid from Capra hircus. Intj of pharm, 2005,304(1-2),4-10.

28. Trickler W, Nagvekar A, Dash A, A novel nanoparticle formulation for sustained paclitaxel delivery. AAPS PharmSciTech, 2008,9(2),486-493.

29. Kale AA and Patrevale VB., design and evaluation of self emulsifying drug delivery system (SEDDS) of nimodipine. AAPS PharmSciTech, 2008,9(1),191-196.

30. Mallikarjun V and Babu RV., Recent trends in development of solid self emulsifying drug delivery (SSEDDS) systems: an overview. Int res j of pharm. 2011, 2(6),18-22. 